\title{
Anxiety-related Factors of High School Students Preparing for University Entrance During the COVID-19 Pandemic in Thailand
}

\author{
Plabrat Dijam
}

PSU. Wittayanusorn School, Songkhla, Thailand

\begin{abstract}
In every student's life, preparing for university admission is considered to be one of the highest priorities. Thai University Center Admission System (TCAS) offers 3 routes (or rounds) for students to enter universities which is called TCAS round1, round 2 and round 3. "This study sought to explore anxiety levels and anxiety - related factors during the COVID-19 pandemic amongst high school students who aim to further study at a university level. We sampled Thai high school students by cluster sampling method. Students responded to a Google form questionnaire that had 3 sections: 1. Personal information 2. Anxiety - related questions 3 . The 7 . item Generalized Anxiety Disorder Scale (GAD-7). The results show that 302 out of 315 participants, which is 95.87\%, agree that COVID-19 affects their university preparation. The average GAD-7 score of those 302 participants is 9.189. Gender also contributes to the difference in anxiety scores. Women tend to have a higher average anxiety score than men. In addition, the study reveals positive correlations between anxiety - related factors and GAD-7 scores. Furthermore, these factors are found to be positively related to each other. Regarding TCAS, since each round has a clearly contrasting method of entry to the universities, the average anxiety scores of each method also differed. Unexpectedly, the average GAD-7 score of students in TCAS round 1 is higher than that of TCAS round 3. While the number of competitors in TCAS round 1 is a lot less than that of TCAS round 3, the ratio between successful applicants and total applicants is a lot higher. This clearly shows that the anxiety level is more affected by the competitive rate compared to the number of competitors.
\end{abstract}

Keywords: Anxiety, High school students, COVID-19, University preparation, GAD-7, TCAS, Tertiary education

\section{Introduction}

In today's world, resources are insufficient for the increasing demands of society. Consequently, various competitive societies have been formed, especially when it comes to education. University preparation is one of the most essential aspects of a high school students' life. Under Thailand's education system, university entry requires students to choose either one of the three rounds in the "Thai University Central Admission System" (TCAS) where TCAS round 1 is based on a portfolio, TCAS round 2 is based on regional quotas for suburban students, and TCAS round 3 is a direct admission system.

The belief that a university degree is considered a key to the door of success has been passed down for many generations. High School students tend to struggle to find one's desired major and college. While the social pressures keep weighing them down, many students start to suffer from an anxiety disorder. Anxiety disorder - a universal adaptive response to a threat - is becoming more common in the younger generation nowadays ${ }^{1}$. This has been particularly prevalent during the COVID-19 pandemic which has had devastating effects in many circumstances, such as having less time to prepare, online learning which is ineffective, many activities having to be postponed, and the decline of family income.

According to the reasons mentioned above, this study aims to explore and compare the anxiety - related factors; genders, TCAS rounds, and the impacts from the COVID-19 crisis through the GAD-7 test - an easy to use, highly

\footnotetext{
${ }^{1}$ Bruce and Tony. (2017). Anxiety, Primary Care Mental Health. (p.145-155). Royal College of Psychiatrists
}

accurate, valid and efficient tool for screening for GAD (Generalised anxiety disorder) and assessing its severity in clinical practice and research ${ }^{2}$.

\section{Methodology}

To begin with, we conducted a Google form questionnaire in order to identify the various factors that contribute to determining the anxiety levels of 315 high school students in pursuing a particular major at the university level. The questionnaire began by asking about the respondents gender followed by their desired major and TCAS round. 6 choices were given for the desired major: 1. Medicine 2 . Engineering 3. Dentistry 4. Accountancy 5. Architecture 6. Others. From all the various disciplines of tertiary studies, these 6 majors have been selected as they are shown to be the most eminent majors that high school students tend to pick. In addition to that, GAD-7 (Generalized Anxiety Disorder - 7) was given to measure the level of anxiety rating on a scale of 0 - 21. Afterwards, the survey participants were given 4 statements each representing the different impacts caused by the COVID-19 pandemic in Thailand. Each statement requires a scale from 1 - 5 for the survey - takers to rate from: with 1 being strongly disagree and 5 being strongly agreeing. We focused on the levels of anxiety of high school teenagers, ranging from grade 10 to grade 12 or Mathayom 4 to Mathayom 6 in the Thai education system.

2 Robert L. Spitzer, MD; Kurt Kroenke, MD; Janet B. W. Williams, DSW. 2006. A Brief Measure for Assessing Generalized Anxiety Disorder. Columbia University 
Table 2.1: Questionnaire Template

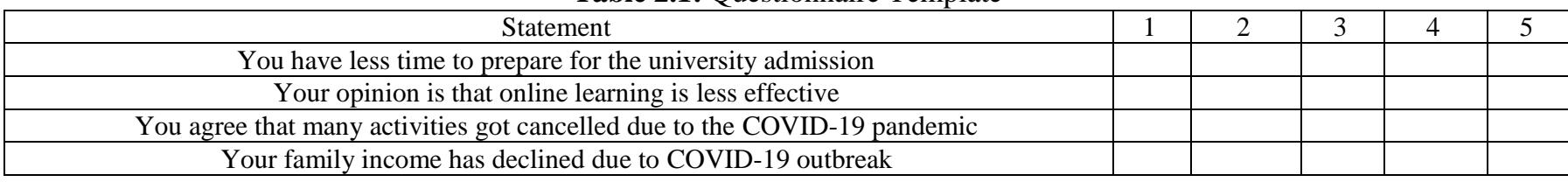

Table 2.2: GAD-7 (Generalized Anxiety Disorder - 7)

\begin{tabular}{|c|c|c|c|c|}
\hline Question & Not at all & Several days & More than half the days & Nearly everyday \\
\hline Feeling nervous, anxious or on edge & 0 & 1 & 2 & 3 \\
\hline Not being able to stop or control worry & 0 & 1 & 2 & 3 \\
\hline Worrying too much about different things & 0 & 1 & 2 & 3 \\
\hline Trouble relaxing & 0 & 1 & 2 & 3 \\
\hline Being so restless that is hard to sit still & 0 & 1 & 2 & 3 \\
\hline Becoming easily annoyed or irritable & 0 & 1 & 2 & 3 \\
\hline Feeling afraid as if something awful might happen & 0 & 1 & 2 & 3 \\
\hline
\end{tabular}

The data gathered from the survey was analyzed using various means of calculations to deduce a conclusion and explore the effects of different anxiety - related factors.

Table 2.3: Number of respondents

\begin{tabular}{|c|c|c|c|c|c|c|}
\hline & Medicine & Engineering & Dentistry & Accountancy & Architecture & Others \\
\hline No. respondents & 113 & 39 & 26 & 14 & 12 & 111 \\
\hline
\end{tabular}

\section{Results and Discussion}

Table 3.1: Student's anxiety scores based on their desired majors and TCAS rounds.

\begin{tabular}{|c|c|c|c|c|c|c|c|}
\hline & Medicine & Dentistry & Engineering & Accountancy & Architecture & Others & Total \\
\hline TCAS Round 1 & 9.206 & 9.667 & 8.444 & 10.75 & 7.658 & 8.078 & 9.528 \\
\hline TCAS Round 2 & 8.652 & 7.889 & 7.2 & 7.134 & 4 & 6.957 & 8.286 \\
\hline TCAS Round 3 & 9.071 & 9.286 & 8.272 & 10.375 & 7.744 & 8.851 & 9.117 \\
\hline Average & 8.976 & 8.947 & 7.972 & 9.42 & 6.467 & 7.962 & 8.977 \\
\hline
\end{tabular}

The table above compares the average calculated anxiety scores of the 3 different TCAS rounds varying on their selected majors. The various majors consist of 1 . Medicine 2. Dentistry 3. Engineering 4. Accountancy 5. Architecture 6. Others. Overall, it is apparent that students who prepared for TCAS round 2 have the lowest anxiety, and students who prepared for round 1 have the highest anxiety of all 3 rounds. Moreover, Accountancy has a mean score of 9.420 which is the highest compared to the other faculties. On the other hand, Architecture has the lowest mean score of 6.467.

Table 3.1.1: Number of participants of Thai university admission in 2020

\begin{tabular}{|c|c|c|c|}
\hline TCAS Round & $\begin{array}{c}\text { No. of } \\
\text { successful } \\
\text { applicants }\end{array}$ & $\begin{array}{c}\text { No. of total } \\
\text { applicants }\end{array}$ & $\begin{array}{c}\text { The ratio between } \\
\text { successful applicants } \\
\text { and total applicants }\end{array}$ \\
\hline TCAS Round 1 & 101,097 & 151,609 & 0.667 \\
\hline TCAS Round 2 & 67,235 & 111,757 & 0.602 \\
\hline TCAS Round 3 & 91,950 & 111,725 & 0.823 \\
\hline
\end{tabular}

Table 3.1.1. not only depicts the total number of participants and the participants who passed the university admission, but it also calculates the ratio between the 2 pieces of information.

As can be seen from the tables above, the calculated anxiety score from TCAS round 1 is the highest with the score of 9.528 followed by TCAS round 3 and 2 with the score of 9.117 and 8.286 respectively. As a result of the variation of competitions along with the number of participants in each round, the ratio between the number of accepted participants and the total number of participants of each TCAS round is investigated through mathematical calculation. Arranging the ratios in the descending order, the highest ratio from TCAS was round 3 , round 1 and round 2 with the figures of $0.823,0.667$ and 0.602 accordingly.

The impact of competitive rates on anxiety

In "Competition, Anxiety, and Depression in the College Classroom: Variations by Student Identity and Field of Study", Jullie R. Posselt said "High levels of competition have a positive relationship with depression and anxiety" However, the results of this study differ from the proclaimed conclusion. For instance, the round with the highest ratio of competitiveness, round 3 , has a lower anxiety score than round 2. This is a consequence of the different processes of each round. The procedure of TCAS round 1 consists of a portfolio and interview which unfortunately has the lowest chance of getting admitted, thus students need to prepare a fallback plan. Additionally, this path also brings forward the registration date. This actively demonstrates that a decrease in time for preparation heightens anxiety which corresponds to Shauna Orfus' conclusion that " Time pressure is a component of test anxiety "3. As TCAS round 3 only requires students to take part in national examinations, students have a clear overview of their preparation plans. For all these reasons, the average anxiety score in TCAS round 3 is less than that of TCAS round 1 although the applicants are greater.

\footnotetext{
${ }^{3}$ Shuana Orfus.(2008).The Effect Test Anxiety and Time Pressure on Performance. (p.120-121).Huron University
} 
Table 3.2: Students' anxiety scores based on their genders and their opinions about the statement "COVID-19 affect your college preparation"

\begin{tabular}{|c|c|c|c|c|c|c|}
\hline \multirow{2}{*}{ Gender } & \multicolumn{4}{|c|}{ Opinions of students about the statement "COVID-19 affect your college preparation" } \\
\cline { 2 - 7 } & \multicolumn{2}{|c|}{ Agree } & \multicolumn{2}{c|}{ Disagree } & \multicolumn{2}{c|}{ Average total score } \\
\cline { 2 - 7 } & $\begin{array}{c}\text { Average anxiety } \\
\text { score }\end{array}$ & $\begin{array}{c}\text { Number of } \\
\text { participant }\end{array}$ & $\begin{array}{c}\text { Average anxiety } \\
\text { score }\end{array}$ & $\begin{array}{c}\text { Number of } \\
\text { participant }\end{array}$ & $\begin{array}{c}\text { Average Anxiety } \\
\text { score }\end{array}$ & $\begin{array}{c}\text { Number of } \\
\text { participants }\end{array}$ \\
\hline Male & 9.072 & 83 & 3.6 & 5 & 8.761 & 88 \\
\hline Female & 9.233 & 219 & 8.125 & 8 & 9.194 & 227 \\
\hline Total participant & 9.189 & 302 & 6.385 & 13 & 9.073 & 315 \\
\hline
\end{tabular}

The data above measures the mean scores from the GAD-7 test along with the number of the study respondents varying on gender as well as their views on whether their plans for university have been affected by the COVID-19 pandemic.

In general, from the 315 test responses about $95.87 \%$ agree with the already mentioned statement while the rest approximately $4.13 \%$ - disagree with the idea. There are 83 out of 88 male students who agree. The mean score of the 83 people is 9.072 which is noticeably higher than the 3.6 of the 5 males who disagreed. Moreover, the number of female students who agree and disagree are 219 and 8 respectively. Additionally, females who agree with the statement score 9.223 and those who disagree score 8.125. Consequently, the disparity of the mean scores between the two sides is not that easily distinguishable compared to men.

With regards to genders, noticeable differences in anxiety levels between males and females were observed. The average female respondents have a higher anxiety score than male respondents which is 0.433 . According to Angst \& Dobler - Mikola, women are significantly more likely than men to develop an anxiety disorder throughout their lifespan ${ }^{4}$. In addition to that, The National Comorbidity Survey (NCS; conducted from 1990 to 1992) found that lifetime prevalence rates for any anxiety disorder were $30.5 \%$ for women and $19.2 \%$ for men ${ }^{5}$.

Table 3.3: Correlation test among related - factors affecting anxiety

\begin{tabular}{|c|c|c|c|c|c|}
\hline & $\begin{array}{c}\text { Total } \\
\text { anxiety } \\
\text { score }\end{array}$ & $\begin{array}{c}\text { Less time } \\
\text { to prepare } \\
\text { for } \\
\text { university } \\
\text { admission }\end{array}$ & $\begin{array}{c}\text { Online } \\
\text { learning } \\
\text { is less } \\
\text { effective }\end{array}$ & $\begin{array}{c}\text { Many } \\
\text { activities } \\
\text { have been } \\
\text { postponed }\end{array}$ & $\begin{array}{c}\text { Declination } \\
\text { of family } \\
\text { income }\end{array}$ \\
\hline $\begin{array}{c}\text { Total anxiety } \\
\text { score }\end{array}$ & 1 & 0.461 & 0.412 & 0.436 & 0.22 \\
\hline $\begin{array}{c}\text { Less time to } \\
\text { prepare for } \\
\text { university } \\
\text { admission }\end{array}$ & 0.461 & 1 & 0.41 & 0.374 & 0.194 \\
\hline $\begin{array}{c}\text { Online } \\
\text { learning is } \\
\text { less effective }\end{array}$ & 0.412 & 0.41 & 1 & 0.386 & 0.136 \\
\hline $\begin{array}{c}\text { Many } \\
\text { activities } \\
\text { have been } \\
\text { postponed }\end{array}$ & 0.436 & 0.374 & 0.386 & 1 & 0.246 \\
\hline
\end{tabular}

\footnotetext{
${ }^{4}$ Angst J, Dobler-Mikola A. The Zurich Study: V. Anxiety and phobia in young adults. European Archives of Psychiatry and Neurological Sciences. 1985;235(3):171-178.

${ }^{5}$ Kessler RC, Chiu WT, Demler O, Merikangas KR, Walters EE Arch Gen Psychiatry. 2005 Jun; 62(6):617-27.
}

\begin{tabular}{|c|c|c|c|c|c|}
$\begin{array}{c}\text { Declination } \\
\text { of family } \\
\text { income }\end{array}$ & 0.22 & 0.194 & 0.136 & 0.252 & 1 \\
\hline
\end{tabular}

As indicated in the figures above, we can deduce that the relations between the anxiety - related factors and total anxiety score are slightly positive. In addition to that, the table also illustrates the correlation amongst the 4 factors; 1 . Less time 2. Less effective Online Learning 3. Activities Postponement 4. Reduction of Family Income. Negative relations are not shown by any factors.

\subsubsection{Positive Relationship between Total Anxiety Score and related - factors}

From the correlation table above, the correlation between the total anxiety score and the anxiety - related factors indicates a low to medium positive correlation between them which is around 0.220 to 0.461 . The most apparent positive relation is between the Reduction of Time to Prepare for university admission which accounted for 0.461 . This is similar to the latest study of Manal R Alammari which found that $91.67 \%$ of the students agreed that a Lack of Time to Prepare before exams was an anxiety - provoking factor ${ }^{6}$. The lowest positive relation belongs to the Declination of Family Income which scored 0.220. These economic stressors were positively associated with the level of anxiety symptoms during the epidemic ${ }^{7}$. Less effective Online Learning and Activities Postponement show moderate positive relationships which have the correlations of 0.412 and 0.436 respectively; the result of the study between Online Studying and Total Anxiety corresponds to Mirna A. Fawaz's study that Learning through online platforms has given rise to anxiety disorders among undergraduate university students while the latter factor also yields similar results with the study of Yehong Kuang MD that activity restriction is associated with the symptoms of anxiety ${ }^{9}$. Taking the results into consideration, we can deduce that the reasons why the correlations between total anxiety score and the top 3 anxiety - related factors; Less time, Less effective Online Learning and Activities Postponement, are significantly

\footnotetext{
6 Manal R Alammari and Dalea M Bukhary.(2019).Factors contributing to prosthodontic exam anxiety in undergraduate dental students.(p.35-36).King Abdulaziz University

${ }^{7}$ Wenjun Caoa.(2020).The psychological impact of the COVID-19 epidemic on college students in China.(p.4).ChangZhi Medical College, China

${ }^{8}$ Mirna A. Fawaz, PhD.(2020).E-learning : Depression, anxiety, and stress symptomatology among Lebanese university students during COVID-19 quarantine.(p.52).Beirut Arab University

9 Yehong Kuang MD.(2020).Association of outdoor activity restriction and income loss with patient-reported outcomes of psoriasis during the COVID-19 pandemic: A web-based survey.(p.3).Central South University, China
} 
higher than the Declination of Family Income is because the top 3 anxiety - related factors directly affect the study efficiency of high schoolers. On the contrary, family income situations only have indirect impacts on anxiety and study efficiency.

\subsubsection{Positive Relationship between Anxiety - related factors}

As can be seen from the table above, the information shows the relationships between the four anxiety - related factors. It shows which factors are more likely to appear together in students. In addition, it also shows that these factors are related to anxiety. Starting from the highest to the lowest correlation, the correlation between Reduction of Time to Prepare for University Admission and Less effective Online Learning is 0.410 yields the highest score.

This is followed by Less effective Online Learning and Activities Postponement with the correlation of 0.386 , Activities Postponement and Reduction of Time to Prepare for University Admission scoring 0.374, The Declination of Family Income and Activities Postponement scoring 0.252, Activities Postponement and Declination of Family Income scoring 0.246, the Declination of Family Income and the Reduction of Time to Prepare scoring 0.194, and finally, the lowest correlation with the score of 0.136 is between the Declination of Family Income and Less effective Online Learning. It is noticeable that the correlation between the Declination of Family Income and other anxiety - related factors appears to be less than the other correlations between other anxiety - related factors. As previously mentioned, family income situations impact anxiety and study efficiency indirectly due to the fact that it is not a student's responsibility since family income is a problem that is usually left to be dealt with by parents.

\section{Conclusion}

Out of 315 respondents, 312 respondents, approximately $95.873 \%$, have experienced anxiety due to the university admission process during the COVID-19 pandemic in Thailand. Based on this study we can conclude that the average anxiety score in each TCAS round depends on the competitive rate, where TCAS round 1 has the highest score, and TCAS round 2 has the lowest. Among many faculties in this study, the students who want to study accountancy have the highest anxiety score whereas architecture has the lowest anxiety score. However, genders play a moderate role, since it can be seen that the anxiety score of females is only slightly higher than males. The study also includes anxiety related factors that are associated with the COVID-19 situation. This consists of The Reduction of Time to Prepare for university admission, Less effective Online Learning, Activities Postponement and Reduction of Family Income. The data gathered also exhibits a conclusive correlation between different anxiety - related factors.

Firstly, the correlation between the total anxiety score and every anxiety - related factor is convincingly positive with the highest positive correlation and the lowest positive correlation being The Reduction of Time to Prepare and The Declination of Family Income respectively. In addition, we can also conclude that the correlation amid the anxiety - related factors is slightly positive. The correlation between Reduction of Time to Prepare for university admission and Online Learning yields the highest score, whereas the correlation between The Declination of Family Income and Less effective Online Learning-yields the lowest. There are many factors that can affect one's anxiety during the COVID-19 pandemic. COVID-19 has had a tremendous impact on university entrance for Thai students in every TCAS round. More significantly, it is crucial for high schoolers to prepare their routes for University as soon as possible, lest the situation be further aggravated by COVID19.

\section{References}

[1] Amir Moghani Bashi - Mansourieh.2020. Assessing the anxiety level of Iranian general population during COVID-19outbreak

[2] Angst J, Dobler - Mikola A. The Zurich Study: V. Anxiety and phobia in young adults. European Archives of Psychiatry and Neurological Sciences. 1985; 235 (3): 171-178.

[3] Bruce and Tony. (2017). Anxiety, Primary Care Mental Health. (p.145 - 155). Royal College of Psychiatrists

[4] Bruce SE, Yonkers KA, Otto MW, Eisen JL, Weisberg RB, Pagano M, Shea MT, Keller MB, Am J Psychiatry.2005 Jun; 162 (6): 1179 - 87.

[5] Kessler RC, Chiu WT, Demler O, Merikangas KR, Walters EE Arch Gen Psychiatry.2005 Jun; 62 (6): $617-27$.

[6] Manal R Alammari and Dalea M Bukhary. (2019). Factors contributing to prosthodontic exam anxiety in undergraduate dental students. (p.35 - 36). King Abdulaziz University

[7] Mirna A. Fawaz, PhD. (2020). E - learning: Depression, anxiety, and stress symptomatology among Lebanese university students during COVID19 quarantine. (p.52). Beirut Arab University

[8] Posselt, Julie R.; Lipson, Sarah Ketchen (2016). Competition, Anxiety, and Depression in the College Classroom: Variations by Student Identity and Field of Study. Journal of College Student Development, 57 (8), 973-989.

[9] Robert L. Spitzer, MD; Kurt Kroenke, MD; Janet B. W. Williams, DSW.2006. A Brief Measure for Assessing Generalized Anxiety Disorder. Columbia University

[10] S. Ajmi et al. (2021). Anxiety on the lockdown resolution. Sfax. Tunisia

[11] Shuana Orfus. (2008). The Effect Test Anxiety and Time Pressure on Performance. (p.120 - 121). Huron University

[12] Wenjun Caoa. (2020). The psychological impact of the COVID-19 epidemic on college students in China. (p.4). ChangZhi Medical College, China

[13] Yehong Kuang MD. (2020). Association of outdoor activity restriction and income loss with patient reported outcomes of psoriasis during the COVID-19 pandemic: A web - based survey. (p.3). Central South University, China 